Revista

Multi-Ensayos

Vol. 5, $\mathrm{N}^{\circ} 10$

ISSN: 2412-3285

https://multiensayos.unan.edu.ni

DOI: https://doi.org/10.5377/multiensayos.v5i10.8869

\title{
La mediación pedagógica y el texto paralelo: una experiencia enriquecedora
}

\section{Pedagogical mediation and parallel text: an enriching experience}

\author{
Ana Teodora Téllez Flores ${ }^{1}$
}

Recibido: 25 de mayo de 2019. Aceptado: 24 de junio de 2019

\section{RESUMEN}

Este ensayo aborda la experiencia relacionada con la elaboración de un texto base, mediado pedagógicamente en la asignatura de Química Ambiental, así como las lecciones y aprendizajes vividos por los estudiantes en la construcción de sus textos paralelos. Un texto educativo mediado pedagógicamente, trata el contenido y la forma de expresarlo de manera clara, accesible y creativa. Así también, es importante enfatizar en la relevancia que tiene el no perder de vista a los discentes, como sujetos activos en la construcción consciente de sus aprendizajes. En este mismo orden, en la mediación pedagógica resultan fundamentales tres aspectos: el tratamiento desde el contenido, desde la forma y desde el aprendizaje. Es necesario que estos elementos estén presentes en todas las etapas del diseño del texto base. Otros elementos que no podemos dejar de considerar son: la contextualización de las temáticas con datos y situaciones relacionadas con el perfil de la carrera, así como el estímulo hacia una actitud investigativa. De este modo, como educadores universitarios estaremos contribuyendo de forma paulatina a que el proceso de aprendizaje sea una actividad lúdica, creativa, placentera y bella.

Palabras claves: mediación pedagógica; texto paralelo; educación superior.

\section{ABSTRACT}

This essay addresses the experience related to the elaboration of a basic text, mediated pedagogically in the subject of Environmental Chemistry, as well as the lessons and learnings experienced by students in the construction of their parallel texts. A pedagogically mediated educational text addresses the content and how to express it in a clear, accessible and creative way. It is also important to emphasize the relevance of not losing sight of the speakers, as active subjects in the conscious construction of their learnings. In this same order, three aspects are essential in pedagogical mediation: treatment from content, form and learning. These elements need to be present at all stages of the base text design. Other elements that we cannot fail to consider are: the contextualization of the themes with data and situations related to the profile of the race, as well as the encouragement towards an investigative attitude. In this way, as university educators we will be contributing gradually to make the learning process a playful, creative, pleasant and beautiful activity.

Keywords: pedagogical mediation; parallel text; higher education.

1 Docente UNAN-Managua/FAREM-Estelí. Correo electrónico: anatellezf@yahoo.com. (c) 2019 Revista Multi-Ensayos. 


\section{INTRODUCCIÓN}

En el ámbito educativo, un tema de gran importancia es la mediación pedagógica. Esta temática está contenida en la obra del mismo nombre, escrita por Gutiérrez y Prieto (1996). En esta ocasión, inicio este escrito adhiriéndome a las palabras de los mencionados autores, quienes afirman que en la educación universitaria es relevante la presencia de un discurso educativo mediado pedagógicamente. Enfatizan que, no solamente en la relación presencial, también en los materiales que elaboramos para nuestros estudiantes, mismos éstos que es donde está la ciencia, para que entren a ella con amor y no con esfuerzo.

Cabe mencionar que, el libro de texto base de Química Ambiental, tal como lo sugiere la mediación pedagógica, contempla en cada capítulo sugerencias de aprendizaje relacionadas con actividades experimentales en casa (ej. detectores ambientales), estudio de casos, observaciones ambientales a los miembros de la familia, registro de experiencias relacionadas con el contexto, reflexiones, discusiones con sus compañeros, entre otras. Para ello, se sugiere a los estudiantes realicen una lectura reflexiva analítica, crítica y comprensiva, tanto individual como en equipo. De modo que éstos elaboraron el texto paralelo a medida que interpretaban, comparaban, compartían, analizaban y reflexionaban en torno al contenido de las distintas unidades temáticas.

\section{DESARROLLO}

Tal y como lo menciona la literatura científica, la pedagogía se ocupa del sentido del acto educativo y éste consiste en seres humanos que se relacionan para facilitar procesos de aprendizaje y aprender conscientemente.

Gutiérrez \& Prieto (1996: xiv), consideran que:

"No son los simples conocimientos los que dan sentido a la vida, sino su integración a procesos de aprendizaje y a la realización humana. Una universidad anclada en el traspaso de conocimientos, termina por perder su sentido: el de la formación de seres humanos. No es con datos como éste que se logra, sino por la pasión de la comunicación, por la realización humana, por la aventura de realizarse como persona, a partir de la construcción de conocimientos, de la creatividad, de la investigación, del intercambio de experiencias".

Por lo antes expuesto, la mediación pedagógica implica concebir a las personas como sujetos activos de su propio aprendizaje. Por ello, en el aula de clase la relación con el educando surge del trabajo de facilitación o mediación que realiza el docente y depende del amor, dominio y pasión que éste tenga por la docencia. "En un sistema a distancia los materiales encarnan esa pasión y son ellos los que permiten al estudiante encontrar y concretar el sentido del proceso educativo" (Gutiérrez \& Prieto 1996: xiv). Efectivamente, somos los docentes los responsables de avivar esa pasión en los materiales educativos, para poner a nuestros estudiantes en acción y en marcha hacia la facilitación de procesos de aprendizaje significativos. 
En este pnto, en sintonía con Gutiérrez y Prieto (1996) conviene compartir, de manera sintética que la mediación pedagógica se concreta en tres fases o tratamientos:

- Tratamiento desde el tema

- Tratamiento desde el aprendizaje

- Tratamiento desde la forma

Así pues, la mediación pedagógica empieza desde el tratamiento desde el tema, que consiste en la información necesaria que contribuirá a la comprensión y apropiación consciente de las temáticas. El mismo comprende cinco aspectos: ubicación temática, tratamiento del contenido, estrategias del lenguaje, conceptos básicos y recomendaciones generales.

Ahora bien, es de suma importancia que la información que les brindemos a nuestros estudiantes sea accesible, clara y bien organizada. De modo que, la misma se organice en función del autoaprendizaje enriqueciéndola desde nuestra experiencia y conocimientos. Por ello, es necesario contextualizarla con datos y situaciones relacionadas con el perfil de su carrera, así como de la realidad nacional, regional y mundial. Kepfer (1991), alude que:

Si la realidad puede ser vivenciada como "actualidad" por el docente y participa de ella en su interactuar con los demás, éstos también se actualizan a través del estilo comunicativo empático, intuitivo y congruente que transmite el ser enseñando.

No está demás que, recordemos que escribimos para nuestros estudiantes, para que estos sean sujetos de su propio aprendizaje. Y como lo expresan los autores de la mediación pedagógica es fundamental que, los educandos sean tomados en cuenta y que estén siempre presentes en el texto. Por ello, se dialoga, estableciendo una comunicación empática, como condición base de todo aprendizaje.

En la segunda fase, el tratamiento desde el aprendizaje, se elaboran los ejercicios o sugerencias de aprendizaje, mismos estos que pretenden conseguir un enriquecimiento del texto. Esto, teniendo en cuenta la experiencia y el contexto de los estudiantes, así como una orientación clara hacia el autoaprendizaje e interaprendizaje, la evaluación y la autoevaluación. Con la elaboración sistemática de dichas sugerencias, a medida que van avanzando en la lectura del texto base, los estudiantes van construyendo el texto paralelo, en el compartir e interactuar con el texto, con los otros y consigo mismo.

Por último, el tratamiento desde la forma, que es la expresión del contenido conjugando lo escrito con lo icónico. Aquí, la belleza de las palabras en armonía con las imágenes (fotos, dibujos, color, contraste, otros) y la diagramación (cuadros, espacios, descansos visuales, otros) es fundamental. Esto, porque hace más comprensible el texto y por ende enriquece los contenidos; facilitando el proceso de aprendizaje. Como bien lo afirman los estudiosos de la mediación pedagógica, la forma también educa, ya que favorece una intensificación significativa al texto. 
Ahora bien, la mediación pedagógica en consonancia con la disponibilidad de la tecnología, nos invita a los docentes a actualizarnos permanentemente. Así también, a repensar nuestra práctica educativa en la búsqueda de la mejora continua del proceso educativo. Ello, en vista que es fundamental para facilitar el autoaprendizaje, la construcción de conocimientos y la actitud investigativa. Así, contribuiremos a que el aprender sea una actividad lúdica, creativa, placentera y bella, como bien lo señalan Gutiérrez y Prieto. Precisamente es ahí donde está nuestro papel, el de ser garantes o facilitadores de aprendizajes conscientes y llenos de significado.

Ahora me referiré, a la experiencia de aprendizaje vivida en la asignatura de Química Ambiental, que compartí con estudiantes de III año de la carrera de Ingeniería Ambiental de nuestra Facultad (FAREMEstelí, UNAN-Managua). Estos elaboraron su texto paralelo en equipo, a medida que iban avanzando en la lectura del texto base de la materia en cuestión. Indagaban, observaban, experimentaban, reflexionaban y hacían análisis crítico de situaciones reales. Al respecto, veamos, lo que uno de los equipos de trabajo expresó:

En este texto paralelo que realizamos, durante todo el transcurso del semestre tratamos de abarcar, todos los conocimientos aprendidos en la clase de Química Ambiental... Y para poder realizar este texto contamos con 4 unidades que logramos llevar a cabo..., desarrollamos cada uno de los tipos de contaminación que existen como: la generada por una industria y hasta la de tipo natural con repercusión en el recurso hídrico, en el suelo y hasta la propia atmósfera...

Es por ello que, estamos viviendo este terrible cambio climático que día a día se va empeorando, porque hacemos caso omiso a tal situación en la que nos encontramos, y en vez de remediar más contaminamos, por lo tanto, solo nos queda adaptarnos al cambio climático, ya que no le tomamos la importancia a nuestro planeta, ni nuestra propia salud... solo nos queda un cambio de actitud...tomar medidas justas y necesarias, en pro de nuestro medio ambiente,... "conciencia y actitud son el camino" para la mejora de nuestra madre tierra.

Es importante mencionar que, el logro alcanzado por los estudiantes en la elaboración de sus textos paralelos es valioso. Ello, a pesar de la incertidumbre que sentían por el estrés que significa emprender una situación nueva y atender otras asignaturas que estaban cursando en el semestre. Así mismo, como lo refirieron, les costaba organizarse y algunos mostraban poca motivación para emprender esta tarea. Sin embargo, es satisfactorio para mí compartirles cómo inicia uno de los equipos de trabajo la ubicación temática de su texto paralelo.

Apreciable lector, queremos contarle que, aunque nos parecía increíble hemos logrado escribir este texto paralelo de Química Ambiental para compartirle a usted el camino recorrido en el proceso de aprendizaje de tan importante asignatura ... el mismo lo fuimos construyendo a medida que avanzábamos en la lectura del texto base elaborado por nuestra docente...le compartimos nuestros conocimientos, experiencias, vivencias, reflexiones, discusiones, experimentaciones y anécdotas relacionadas con nuestro contexto.

Comparto, también lo que nos narra otro equipo referente a un experimento sugerido en uno de los ejercicios del libro de texto base de la asignatura Química Ambiental. Veámoslo a continuación: 


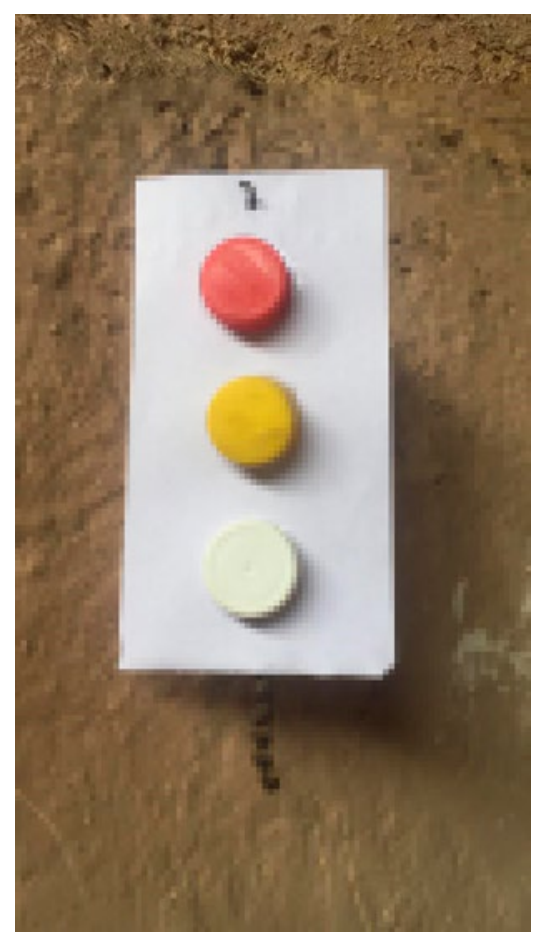

Captadores de contaminación. Foto propia.
En la imagen observamos un experimento para detectar si existe contaminación dentro del hogar. Este experimento consiste en: tomar una hoja de block y cortarla en 3 partes iguales, luego sobre cada uno de los pedazos de hoja colocamos tres tapones, los cuales servirán como detectores de contaminación. El experimento duró 3 semanas, donde se retiraba un tapón cada semana y se realizaba un análisis de los cambios que se presentaban en el papel. La siguiente imagen muestra los puntos de muestreo donde realizamos dicho eperimento. A continuación, se describen los resultados obtenidos a partir del experimento, sobre la contaminación del aire y cuál es el punto más afectado.

... el punto más expuesto a contaminantes, es el punto de la cocina, esto debido a que el fuego emite mucho humo el cual queda impregnado en la hoja de muestreo. El fuego es a base de leña por lo que se emite $\mathrm{CO} 2$ (dióxido de carbono), CO (monóxido de carbono), benceno y muchos otros compuestos que son nocivos para nuestra salud.

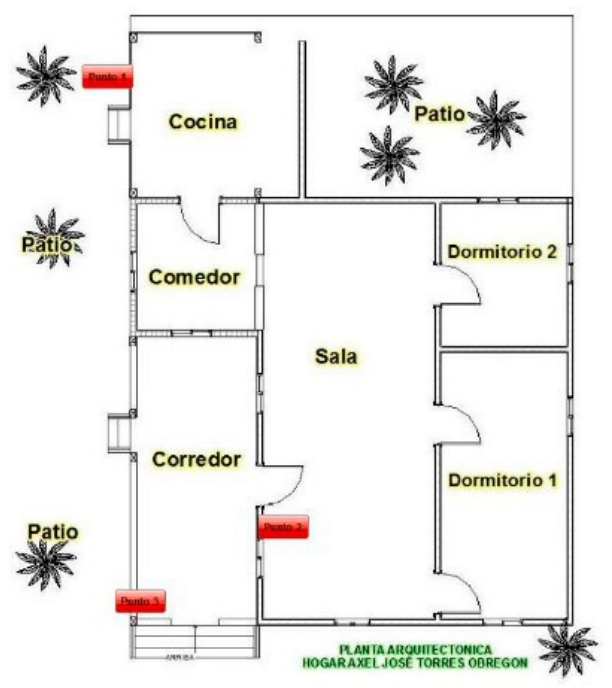

Diseño propio de la vivienda

En este mismo orden, cabe señalar que los estudiantes enriquecieron su texto paralelo integrando en el mismo la giras y laboratorios de campo colegiados. En la última gira de campo evaluaron la calidad y los impactos ambientales en la ruta Santa Cruz, Estelí, Managua y El Crucero. Veamos lo que escribió uno de los equipos al respecto de esta situación.

En el municipio de El Crucero, entrevistamos a personas que sufren los efectos de la lluvia ácida ocasionada por el volcán Masaya. Nos contaron y se observó que los techos de zinc, portones y ventanas de hierro no duran mucho en estos lugares... debido a la corrosión... Otro efecto es que los animales no se desarrollan 
normalmente, presentan frecuentemente dolores en sus patas, otro ejemplo es que el desarrollo de las plantas es lento...Son problemas muy graves y notables, los que pudimos observar en esta ruta... La contaminación en estas ciudades es muy elevada, aunque las podemos mitigar o reducir para darle un mejor equilibrio a los ecosistemas. Por lo tanto, hay que tomar medidas en esto, la excesiva cantidad de automóviles que transitan en Managua son innumerables, y las toneladas de smog que desechan estos automóviles es excesivo.

En las siguientes imágenes se pueden apreciar acciones y observaciones realizadas en esta actividad académica.

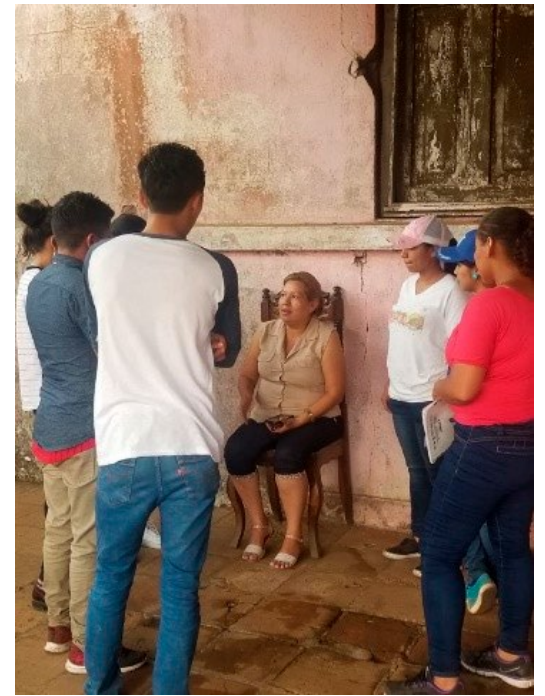

Estudiantes entrevistando a una habitante de El Crucero, Managua.

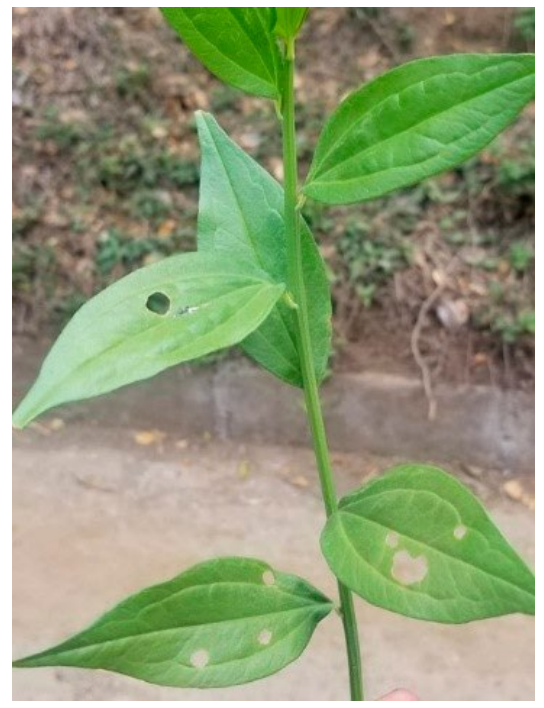

Los agujeros en la planta es otro efecto de la lluvia ácida en El Crucero, Managua.

Finalmente deseo expresarles que en esta experiencia enriquecedora de aprendizaje los estudiantes destacaron lo siguiente: enriquecimos los conocimientos, logramos comprender el objetivo de la Química Ambiental, conocimos ampliamente los tipos de contaminación, comprobamos algunos tipos de contaminación, valoramos nuestro poco tiempo en equipo, aprendimos a trabajar en equipo, respetamos las opiniones de nuestros compañeros y obtuvimos extensas explicaciones de la clase, pero sobre todo muy clara.

\section{CONCLUSIÓN}

Como se puede apreciar, en esta maravillosa interacción, intercambiamos conjuntamente conocimientos, vivencias y emociones que suscitaron un aprendizaje significativo.

En suma, la mediación pedagógica y su técnica el texto paralelo, es una experiencia enriquecedora, ya que favorece una comunicación dialógica empática entre el docente y el discente. Esto se da, si tomamos en cuenta los conocimientos y experiencias previas del estudiantado. Y tal como alude Juárez, (1991, p. 57): 
El docente trata de compartir experiencias, cuando verdaderamente es docente. Es decir, cuando la experiencia sobre su especialidad le permite evaluar los fenómenos que se dan a su alrededor, cuando alcanza la madurez docente.

El estudiante trata de explicase los fenómenos que se dan a su alrededor, cuando verdaderamente es estudiante. Es decir, cuando trata de comprender su medio, cuando alcanza la madurez de estudiante.

\section{REFERENCIAS}

Gutiérrez, F y Prieto, D. (1996). Mediación Pedagógica. Guatemala: Instituto de Investigaciones y Mejoramiento Educativo, Universidad de San Carlos de Guatemala.

Juárez, M.(1992). Comunicación y educación. Guatemala: Instituto de Investigaciones y Mejoramiento Educativo, Universidad de San Carlos de Guatemala.

Kepfer, R. (191). Aprender siendo, ser enseñando. Guatemala: Instituto de Investigaciones y Mejoramiento Educativo, Universidad de San Carlos de Guatemala. 